Complex

mental

functions

\section{Kevin Connolly}

Mind in Society: The Development of Higher Pyschological Processes. By L. S. Vygotsky. Edited by M. Cole, V. John-Steiner, S. Scribner and E. Souberman. Pp. 159. (Harvard University Press: Cambridge, Massachusetts, and London, 1978.) £8.75.

L. S. Vygotsky is known largely to the English reading community through a little book, Thought and Language, which has received very wide acclaim. It was published posthumously in 1934, suppressed in 1936, reissued in 1956 and translated into English only in 1962. The book has had a great impact on Western psychology and revealed Vygotsky as a truly original thinker and insightful observer of children. $\mathrm{He}$ was born in Orsha in Bylorussia in 1896 and graduated from the University of Moscow in 1917 having specialised in literature. From 1917 to 1923 he taught literature and psychology in a school and began his systematic work in psychology only in 1924 . In 1934 at the age of 38 he died of tuberculosis. During this all too brief period of research in psychology he was immensely productive. He worked first at the Institute of Psychology in Moscow and then in the Institute of Defectology, of which he was a founder. Over this 10 year period he taught courses in Moscow and Leningrad, undertook a medical training, and wrote more than 160 books, papers, reviews and lectures. Much of this work remains unpublished and very little has been translated into English. It is now over 40 years since Vygotsky died and yet much of what he had to say is fresh and deeply significant for contemporary psychology. This newlytranslated material is of historical interest but not primarily so; he was writing clearly about fundamental issues which Western psychology has recently been congratulating itself on having articulated.

Vygotsky was interested in complex mental functions, or as they were more usually called 'higher psychological processes'. He rejected the notion that an understanding of these processes could be gained from an extension of the principles derived from animal psychology, and like the Gestalt psychologists did not believe that an adequate analysis was to be found in reductive stimulus-response theories. He sought a comprehensive approach which would provide both description and explanation in terms acceptable to natural science. His goals for such a programme were imensely ambitious including as they did the identification of relevant brain mechanisms, the developmental history of behaviour, and most important specifying the societal context in which the behaviour developed. That he did not fully achieve these goals is hardly surprising but he did show himself to be an astute and remarkable thinker.

For Vygotsky the developmental method is a central feature of psychological science. He saw the scientist's task as one of reconstructing the origin and course of the development of behaviour and consciousness. A distinctive theme of his writing is the emphasis which he placed upon the unique qualities of man. As a species we actively realise and change ourselves in the varied contexts of history and culture; in the course of his history man affects and changes nature to create for himself new conditions of existence. To the Western tradition Vygotsky seems less an experimenter and more a thinker. He was a brilliant observer of children and an ingenious experimenter, but his work is not characterised by elaborate experimental designs and statistical analyses. Rather the experiment is a means of gaining insights which illuminate the ideas and carry them along. The experimental 'leg work' will no doubt be done by others, who perhaps find thinking harder.

The book contains eight of Vygotsky's essays, the first five of which are taken largely from a hitherto unpublished manuscript of 1930 entitled, Tool and Symbol in Child Development. Here Vygotsky attempts to relate Marx's Theory of Society to concrete psychological questions. The concept of tool implies a specific human activity, the transforming effect man has upon nature in gaining mastery over it to serve his ends. Like tool systems, sign systems (speech, writing, number) are created by societies and change with the level of cultural development. In this way the mechanism of individual developmental change is rooted in society and culture. The last three essays explore educational implications of his ideas. Again the penetrating quality of his thought is striking. $\mathrm{He}$ explores the relationship between learning and development, and in his concept of the "zone of proximal development" can be seen the antecedents of the competence/ performance distinction which psychologists have made much of over the

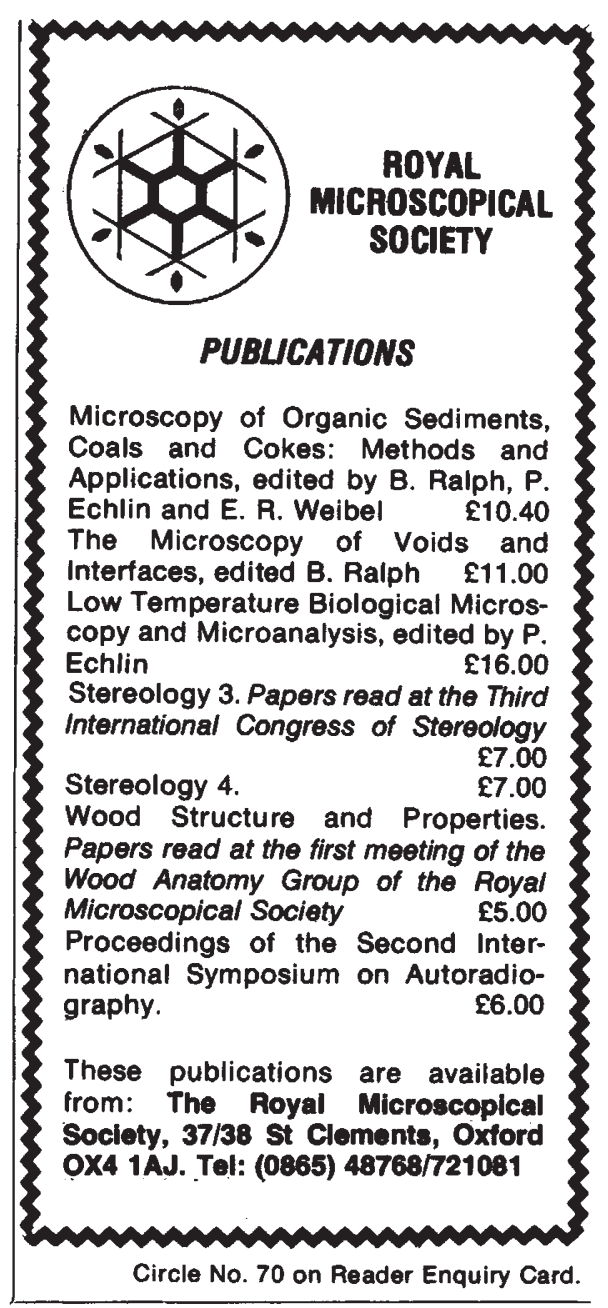

past decade. He proposes too that intelligence could be better assessed by an examination of the child's capacity to benefit from teaching rather than the normative comparisons embodied in psychometric tests. In an essay on play he concludes that it is not a predominant feature of childhood but that it is a leading factor in development. The last essay on writing is a masterpiece which has profound practical implications in education.

This little book is an intellectual excitement; it abounds with all manner of ideas, insights and novel formulations. For anyone feeling jaded with contemporary cognitive or developmental psychology the book should lift the spirit; for the graduate student in search of ideas it cannot fail to raise and widen the horizons. The editors provide, two by two, a useful and sharply focused introduction and concluding piece.

Vygotsky comes high on my list of people I regret not having met and I am grateful to the editors for having helped me know him in the next best way. I recommend the book warmly and without reservation.

Kevin Connolly is Professor of Psychology at the University of Sheffield, UK. 